\title{
Phlox Species Show Quantitative and Qualitative Resistance to a Population of Powdery Mildew Isolates from the Eastern United States
}

\author{
Coralie Farinas, ${ }^{1}$ Pablo S. Jourdan, ${ }^{2}$ Pierce A. Paul, ${ }^{3}$ Jason C. Slot, ${ }^{1}$ Margery L. Daughtrey, ${ }^{4}$ Veena Devi Ganeshan, ${ }^{1}$ \\ Fulya Baysal-Gurel, ${ }^{5}$ and Francesca Peduto Hand, $1, \dagger$ \\ ${ }^{1}$ Department of Plant Pathology, The Ohio State University, Columbus, OH 43210 \\ ${ }^{2}$ Department of Horticulture and Crop Science, The Ohio State University, Columbus, OH 43210 \\ ${ }^{3}$ Department of Plant Pathology, The Ohio State University, Wooster, OH 44691 \\ ${ }^{4}$ Plant Pathology and Plant-Microbe Biology Section, Cornell University, Long Island Horticultural Research \& Extension Center, Riverhead, \\ NY 11901 \\ ${ }^{5}$ Department of Agricultural and Environmental Sciences, Tennessee State University, McMinnville, TN 37110 \\ Accepted for publication 5 April 2020.
}

\begin{abstract}
Ornamental plants in the genus Phlox are extensively planted in landscapes and home gardens around the world. A major limitation to a more widespread use of these plants is their susceptibility to powdery mildew (PM). In this study, we used multilocus sequence typing (MLST) analysis to gain insights into the population diversity of 32 Phlox PM pathogen (Golovinomyces magnicellulatus and Podosphaera sp.) isolates collected from the eastern United States and relate it to the ability to overcome host resistance. Low genetic diversity and a lack of structure were found within our population. Whole genome comparison of two isolates was used to support low genetic diversity evidence found with the MLST analysis. Recombination was suggested by the incongruences observed in the six phylogenetic trees generated from the housekeeping genes TEF- $1 \alpha$, CSI, ITS, IGS, H3, and TUB. Contrasting with low genetic diversity, we found high phenotypic
\end{abstract}

ABSTRACT

Durable disease resistance is the ultimate goal of plant pathology. It is the most environmentally and economically friendly method to manage diseases as it leads to reduced chemical use. Durable resistance comprises the plant's capability to fend off a pathogen's infection and also the failure of the pathogen to overcome plant defense mechanisms, both over the long-term (McDonald and Linde 2002). There are different types of resistance. Qualitative, also known as gene-for-gene resistance, can provide complete immunity and is usually controlled by a dominant gene. Quantitative resistance is controlled by multiple genes, each contributing a relatively small effect, and it is thought to be more durable than qualitative resistance (Cowger and Brown 2019; Mundt 2014). Several resistance deployment strategies for achieving durable resistance have been described, including gene rotation and gene pyramiding, in which several identified resistance genes are used either in replacement or simultaneously to prevent

†Corresponding author: F. P. Hand; hand.81@osu.edu

Funding: This work was partially funded by the Fred C. Gloeckner Foundation through the 2016 New York Florists' Club Grant and the 2017 Research Grant and USDA-National Institute of Food and Agriculture Hatch project \#1020446. The research described in this paper represents a portion of the dissertation submitted by C. Farinas to the Office of Graduate Studies of The Ohio State University to partially fulfill requirements for the Ph.D. degree in Plant Pathology.

*The $\boldsymbol{e}$-Xtra logo stands for "electronic extra" and indicates that two supplementary tables and one supplementary figure are published online.

The author(s) declare no conflict of interest.

(C) 2020 The American Phytopathological Society diversity when using 10 of the 32 isolates to evaluate host resistance in four different Phlox species (P. paniculata 'Dunbar Creek', $P$. amoena OPGC 3598, P. glaberrima OPGC 3594, and P. subulata OPGC 4185) using in vitro bioassays. We observed quantitative and qualitative resistance in all Phlox species and a consistent low disease severity in our control, P. paniculata 'Dunbar Creek'. Taken together, the results generated in this study constitute a robust screening of popular Phlox germplasm that can be incorporated into breeding programs for PM resistance and provides significant information on the evolution of PM pathogens.

Keywords: genetics and resistance, genome comparison, germplasm screening, multilocus sequence typing, mycology, Phlox, population biology, population genetics, powdery mildew the pathogen from losing avirulence genes (Mundt 2014). Plant germplasm is often a resource for finding resistance. For example, when breeding for resistance to powdery mildew (PM), many different studies characterized germplasm to find durable resistance in sunflower, pea, barley, and wheat (Ji et al. 2008; Reddy et al. 2013; Surlan-Momirović et al. 2016; Vaz Patto et al. 2007), among other crops.

Ornamental plants in the genus Phlox are highly popular in landscapes worldwide but also highly susceptible to PM (Armitage 2008; Coombs 2017; Zale and Jourdan 2015). PM diseases are caused by obligate biotrophic pathogens able to generate large populations through the abundant production of asexual spores, which are capable of long-distance dispersal and are responsible for population clonality (Milgroom 2015). Sexually derived chasmothecia primarily function in dormancy and release ascospores to infect new hosts in the spring. PM pathogens most recovered from Phlox are the host-specific fungus Golovinomyces magnicellulatus (U. Braun) V.P. Heluta as well as species of Podosphaera. Takamatsu et al. (2006) proposed that the genus Golovinomyces has its center of origin in North America and that the interaction with its hosts has evolved through time, resulting in tremendous diversity of the genus. Therefore, this suggests that Golovinomyces species have large genetic diversity and a high degree of genotype flow (=movement of asexual propagules). McDonald and Linde (2002) hypothesized that genotype flow presents a high evolutionary potential that is likely to overcome genetic resistance because it represents a linked package of coadapted alleles that have already been selected for over time. The genome of $G$. magnicellulatus has been sequenced and annotated (Farinas et al. 2019b) using its haploid stage (asexual spores). PM pathogens become diploid 
during sexual reproduction, when sexual recombination is likely to occur. In temperate climates, sexual reproduction is expected to happen at the end of every growing season. Blumeria graminis, the PM pathogen of wheat, is thought to have a maximum of one sexual cycle per year (Wicker et al. 2013). As with other PM pathogen genomes, G. magnicellulatus has a large genome $(130 \mathrm{Mb})$ and contains $40 \%$ repeats. The high repeat content is mostly composed of transposons (Spanu et al. 2010) and is associated with extensive gene reshuffling.

Due to the plant's historical popularity in landscapes and flower arrangements, many outdoor trials have been conducted to assess new Phlox cultivars for resistance to PM (Cartwright et al. 2001; Coombs 2017). Thompson and Svejda (1964) were unsuccessful at identifying resistance in $P$. paniculata $\mathrm{L}$. While 2 of the 49 cultivars included in the study initially showed resistance in field trials, they tended to lose it with time. The Chicago Botanic Garden (Glencoe, IL) has run trials of Phlox species and hybrids to evaluate horticultural characteristics such as bloom quality, and also their resistance to PM (Hawke 1999, 2011). The 1999 review stated that the difference in susceptibility and resistance of garden Phlox to PM depended on its geographic location (Hawke 1999), suggesting that different populations of PM can be found throughout the United States. Zale and Jourdan (2015) noted that triploid cultivars of P. paniculata, specifically 'Robert Poore' and 'John Fanick', were also associated with resistance to PM in the literature. However, other resistant cultivars, such as 'Shortwood', 'David', and 'Delta Snow', were found to be diploid, which indicates that resistance to PM could have several different pathways. The authors advanced the hypothesis that germplasm introduction of wild-collected Phlox could increase genetic diversity and offer strategies for polyploid breeding. Indeed, exploring the genus diversity could help identify new sources of resistance (Armitage 2008). It is important to realize that breeding for resistance has an impact on pathogen populations. Artificial selection happens every time a new resistant cultivar is developed and cultivated, resulting in a decreased number of pathogen genotypes. The Phlox-PM pathosystem is likely subject to genetic selection because of the instant popularity of less susceptible cultivars.

Additionally, the horticulture crop system is different from other crop systems, and in the context of exploring durable resistance, several aspects need to be taken into consideration. Compared with typical row crop production, the horticultural crop system differs in its global trade, heterogeneity, and disease tolerance (Parke and Grünwald 2012). Methods to prevent the movement of pathogens through domestic and global trade are currently not sufficient: infected plant materials are often shipped across borders, as highlighted by Goss et al. (2009) who studied the movement of Phytophthora ramorum through U.S. nursery plants using genetic markers. Moreover, a typical ornamental greenhouse operation grows a large diversity of plants in a relatively small, enclosed environment, and nurseries likewise produce many more different plant species and cultivars than the average farmer. Because of the high value of each individual plant and the market demand for highly attractive foliage and flowers, growers of ornamentals have a very low threshold for disease tolerance, resulting in extensive use of pesticides that contributes to small population sizes and limits genetic diversity (McDonald and Linde 2002).

Hence, this study had the following objectives: (i) to examine the genotypic diversity of a PM pathogen population of isolates collected in the eastern United States to better understand PM pathogen capacity to adapt to new environments and new resistant hosts, and (ii) to identify the range of plant responses to PM infection by using a combination of Phlox species and PM pathogen isolates.

\section{MATERIALS AND METHODS}

Plant material and pathogen isolation. PM-infected Phlox plants were collected from botanical gardens, residential properties, and garden centers across the eastern United States during spring, summer, and fall of 2016 to 2019 (Table 1). Plants were removed from their original location, repotted, boxed and shipped with an appropriate U.S. Department of Agriculture, Animal and Plant Health Inspection Service PPQ 526 permit to the Ornamental Pathology Laboratory at the Ohio State University (Columbus, $\mathrm{OH})$. Once received, each individual plant was enclosed in a plastic bag and placed in a growth chamber (Conviron PGR-15, Controlled Environments Inc., Pembina, ND) at a temperature of $24^{\circ} \mathrm{C}$ during the day and $22^{\circ} \mathrm{C}$ at night with a 14 -h photoperiod to induce sporulation. Single spore isolates were then cultured on detached $P$. paniculata 'Starfire' leaves maintained in vitro following the protocol described by Farinas et al. (2019a). From each sampling location, one or more single spore isolates were obtained from different leaves of the same plant sample (Table 1). Between 2016 and 2019, we obtained 32 isolates from infected Phlox plants collected across Eastern U.S. states. All isolates but one were from $P$. paniculata cultivars, and all isolates but one were identified as G. magnicellulatus (Table 1).

Genotype characterization. Molecular genotyping. Total genomic DNA was extracted from single spore cultures using a Chelex extraction method (Walsh et al. 1991). PCR was performed using primer pair ITS4/ITS5 (White et al. 1990) following the protocol of Matsuda and Takamatsu (2003) to identify isolates to the genus level. Five additional primer sets (Table 2) targeting the nuclear loci translation elongation factor alpha (TEF-1 $\alpha$ ), chitin synthase I (CSI), histone (H3), $\beta$-tubulin (TUB), and partial intergenic spacer (IGS) were designed (Primer-BLAST, NCBI) by aligning publicly available sequences (KR815572.1, KR815611.1, KR815689.1, KR815650.1, and KR815805.1, respectively) of G. orontii (Castagne) V.P. Heluta (Pirondi et al. 2016) to the whole genome sequence of G. magnicellulatus strain FPH2017-1 (Farinas et al. 2019b; isolate referred to in this study as OH1). All PCR reactions were performed according to the protocol of Pirondi et al. (2016) adapted to a total volume of $25 \mu \mathrm{l}$. All PCR reagents were purchased from Thermo Fisher Scientific (Waltham, MA) and all oligonucleotides were synthesized by Eurofins MWG Operon (Eurofins Genomics LLC, Louisville, KY). Each reaction contained $2.5 \mu \mathrm{l}$ of $10 \times$ DreamTaq Buffer, $2 \mu \mathrm{l}$ of $25 \mathrm{mM} \mathrm{MgCl}_{2}, 1 \mu \mathrm{l}$ of $10 \mathrm{mM}$ $\mathrm{dNTPs}, 1 \mu \mathrm{l}$ of $10 \mu \mathrm{M}$ of each primer, $0.25 \mu \mathrm{l}$ of DreamTaq DNA polymerase $(5 \mathrm{U} / \mu \mathrm{l})$, and $1 \mu \mathrm{l}$ of extracted DNA. The PCR program was as follows: $95^{\circ} \mathrm{C}$ for $3 \mathrm{~min}, 35$ cycles of $95^{\circ} \mathrm{C}$ for $30 \mathrm{~s}, 52$ to $58^{\circ} \mathrm{C}$ (Table 2) depending on primer set for $30 \mathrm{~s}$, and $72^{\circ} \mathrm{C}$ for $1 \mathrm{~min}$, with a final extension of $72^{\circ} \mathrm{C}$ for $5 \mathrm{~min}$. Amplicons were visualized on $1 \%$ agarose gels stained with GelRed (Biotium Inc., Fremont, CA) following manufacturer's instructions, to confirm presence and size of PCR products. These were then purified using ExoSAP-IT (Affymetrix Inc., Santa Clara, CA) and sequenced in both directions using Sanger sequencing (OSUCCC Genomics Shared Resource, Columbus, $\mathrm{OH}$ ). Forward and reverse nucleotide sequences were aligned, checked for sequencing errors and edited manually, and then aligned with MAFFT v.7.407 (Katoh and Standley 2013) and trimmed again using trimal v.1.4 (Capella-Gutierrez et al. 2009). Consensus sequences were deposited in the GenBank database (Supplementary Table S1).

Polymorphism and phylogenetic analyses. DnaSP v.5 (Librado and Rozas 2009) was used to calculate the following parameters: sequence diversity, including the number of SNPs; departure from an equilibrium-neutral model of evolution (Tajima's D) (Tajima 1989); number of haplotypes (h); haplotype diversity (Hd) (Nei 1987); average number of pairwise nucleotide differences $(\mathrm{k})$ (Tajima 1983); pairwise nucleotide diversity $(\pi)$ (Nei 1987), and nucleotide polymorphism $\left(\theta_{w}\right)$ (Watterson 1975). Maximum likelihood phylogenetic trees were computed using IQ-TREE v.1.6.9 (Chernomor et al. 2016), with the option -m MFP+MERGE (Lanfear et al. 2012) and 100 bootstraps, and visualized using FigTree v.1.4.4 (Rambaut et al. 2018). Because there was bootstrap support for incongruence between the generated trees, a neighbor-net 
phylogenetic network was also built to observe the evolutionary relationship of our population using SplitTree v.4.14.8 (Huson and Bryant 2006).

To verify if the number of $G$. magnicellulatus isolates analyzed in this study could be representative of the genetic diversity of eastern U.S. PM populations, we compared the whole genome sequence of two distantly related isolates $(\mathrm{OH} 1$ and $\mathrm{OH} 2)$. The genome of isolate $\mathrm{OH} 1$ was previously sequenced and assembled (Farinas et al. $2019 \mathrm{~b}$ ) and the same protocol for DNA extraction was used for isolate $\mathrm{OH} 2$. Whole genome sequencing was executed using the Illumina HiSeq PE150 platform (Illumina Inc., San Diego, CA) with $100 \times$ coverage. $\mathrm{OH} 2$ reads (NCBI Biosample number SAMN13608638) were mapped to the reference genome OH1 using Bowtie2 v.2.2.9 (Langmead et al. 2018). SAMTools v.1.3.1 (Li et al. 2009) and VCFTools v.0.1.14 (Danecek et al. 2011) were used to assess the number of single nucleotide polymorphisms (SNPs) and their location on the genome, the percentage of synonymous versus nonsynonymous SNPs, and small insertions and deletions of 1 to $26 \mathrm{bp}$ (INDEL). Lastly, secreted proteins identified in $\mathrm{OH} 1$ were compared with an $\mathrm{OH} 2$ assembly (tblastn) using BLAST v.2.4.0+ to test for gene polymorphism (presence/ absence) to further screen for genetic factors underpinning phenotypic diversity. A threshold of $50 \%$ query coverage and an E-value of 1.2 were used to identify positive matches.

Phenotype characterization. Phlox germplasm screening. Plantlets of $P$. glaberrima OPGC 3594, P. paniculata 'Dunbar Creek', $P$. subulata OPGC 4185, and P. amoena OPGC 3598 were micropropagated from a collection maintained at the Ornamental Plant Germplasm Center (OPGC) in Columbus, OH (Table 3) following the protocol described by Farinas et al. (2019a).

TABLE 1. List of powdery mildew isolates included in this study

\begin{tabular}{|c|c|c|c|c|c|}
\hline Isolate $^{a}$ & Sampling site & $\mathrm{HZ}^{\mathrm{b}}$ & Year & Host & Study \\
\hline VA $1^{d}$ & Botanical garden & 6 & 2016 & Phlox paniculata 'Robert Poore' & $\mathrm{G}, \mathrm{P}$ \\
\hline WI1 & Botanical garden & 5 & 2016 & $P$. paniculata 'Tequila sunrise' & $\mathrm{G}$ \\
\hline MI1 & Commercial nursery & 5 & 2017 & P. paniculata 'Nicky' & $\mathrm{G}, \mathrm{P}$ \\
\hline MI2 & Botanical garden & 5 & 2017 & P. paniculata 'David' & $\mathrm{G}$ \\
\hline MI3 & Botanical garden & 5 & 2017 & P. paniculata 'David' & $\mathrm{G}$ \\
\hline IA1 & Residential property & 5 & 2017 & P. paniculata & $\mathrm{G}, \mathrm{P}$ \\
\hline NY1 & Residential property & 5 & 2018 & P. paniculata & $\mathrm{G}, \mathrm{P}$ \\
\hline NY2 & Residential property & 5 & 2018 & P. paniculata & $\mathrm{G}$ \\
\hline NY3.1 & Residential property & 5 & 2019 & P. paniculata & G \\
\hline NY3.2 & Residential property & 5 & 2019 & P. paniculata & G \\
\hline NY4.1 & Residential property & 5 & 2019 & P. paniculata & $\mathrm{G}$ \\
\hline NY4.2 & Residential property & 5 & 2019 & P. paniculata & G \\
\hline NY5.1 & Commercial nursery & 5 & 2019 & P. $\times$ arendsii 'Baby face' & $\mathrm{G}$ \\
\hline NY5.2 & Commercial nursery & 5 & 2019 & $P . \times$ arendsii 'Baby face' & G \\
\hline NY6.1 & Garden center & 5 & 2019 & P. paniculata 'Robert Poore' & $\mathrm{G}$ \\
\hline NY6.2 & Garden center & 5 & 2019 & P. paniculata 'Robert Poore' & $\mathrm{G}$ \\
\hline MS1.1 & Residential property & 8 & 2018 & P. paniculata & $\mathrm{G}, \mathrm{P}$ \\
\hline MS1.2 & Residential property & 8 & 2018 & P. paniculata & $\mathrm{G}$ \\
\hline $\mathrm{OH} 1$ & Residential property & 6 & 2017 & P. paniculata & $\mathrm{G}, \mathrm{P}$ \\
\hline $\mathrm{OH} 2$ & Arboretum & 6 & 2017 & P. paniculata 'Shortwood' & $\mathrm{G}, \mathrm{P}$ \\
\hline $\mathrm{OH} 3.1$ & Germplasm center & 6 & 2018 & P. paniculata $\mathrm{PZ11-044}$ & $\mathrm{G}, \mathrm{P}$ \\
\hline $\mathrm{OH} 3.2$ & Germplasm center & 6 & 2018 & P. paniculata PZ11-044 & $\mathrm{G}$ \\
\hline $\mathrm{OH} 4.1$ & Botanical garden & 6 & 2018 & P. paniculata 'David' & $\mathrm{G}, \mathrm{P}$ \\
\hline $\mathrm{OH} 4.2$ & Botanical garden & 6 & 2018 & P. paniculata 'David' & $\mathrm{G}$ \\
\hline $\mathrm{OH} 4.3$ & Botanical garden & 6 & 2018 & P. paniculata 'David' & $\mathrm{G}$ \\
\hline $\mathrm{OH} 5$ & Wild & 5 & 2018 & P. paniculata & $\mathrm{G}, \mathrm{P}$ \\
\hline OH6.1 & Residential property & 6 & 2019 & P. subulata & $\mathrm{G}$ \\
\hline OH6.2 & Residential property & 6 & 2019 & P. subulata & G \\
\hline TN1.1 & Commercial nursery & 7 & 2019 & P. paniculata 'Flame Purple' & $\mathrm{G}$ \\
\hline TN1.2 & Commercial nursery & 7 & 2019 & P. paniculata 'Flame Purple' & G \\
\hline TN2.1 & Residential property & 7 & 2019 & P. paniculata 'David' & G \\
\hline TN2.2 & Residential property & 7 & 2019 & P. paniculata 'David' & $\mathrm{G}$ \\
\hline
\end{tabular}

${ }^{a}$ Isolates are identified by the U.S. state where they were found $(\mathrm{VA}=$ Virginia; WI = Wisconsin; MI = Michigan; IA = Iowa; NY = New York; MS = Massachusetts; $\mathrm{OH}=\mathrm{Ohio}$; and $\mathrm{TN}=$ Tennessee) along with a sequential number. Isolate numbers separated by a dot indicate that they were retrieved from different leaves of the same plant sample.

${ }^{\mathrm{b}} \mathrm{HZ}=$ hardiness zone. Retrieved from USDA Plant Hardiness Zone Map based on GPS coordinates of sampling sites.

${ }^{c}$ Isolate was used for genotype $(\mathrm{G})$ and/or phenotype $(\mathrm{P})$ characterization experiments.

d Isolate VA1 was identified as Podosphaera sp. All other isolates in the table are Golovinomyces magnicellulatus.

TABLE 2. List of primers designed in this study and used in the multilocus sequence typing analysis

\begin{tabular}{|c|c|c|c|c|}
\hline Locus $^{\mathrm{a}}$ & Primer name & Sequence & Annealing Temp. $\left({ }^{\circ} \mathrm{C}\right)$ & Fragment size (bp) \\
\hline \multirow[t]{2}{*}{ TEF- $1 \alpha$} & tefgmF & GAACCCGCAAGTAGAAAATGGG & 57.7 & 1,307 \\
\hline & tefgmR & GACGTTATCACCAGGAAGACCT & & \\
\hline CSI & cs1gmF & AGCTGTTTATGCTTTGGCTCATTT & 55.0 & 622 \\
\hline \multirow[t]{2}{*}{$\mathrm{H} 3$} & h3gmF & ACCGCTCGCAAGGTATGTATT & 52.8 & 611 \\
\hline & h3gmR & AGACGACGAGCGAGCTGAAT & & \\
\hline \multirow[t]{2}{*}{ TUB } & tub2 $\mathrm{gmF}$ & ATGTTCATCAAАCTCCTGCTTCAAC & 52.0 & 800 \\
\hline & tub2gmR & CACCTTCTGTGTAATGTCCTTTGG & & \\
\hline
\end{tabular}

${ }^{\mathrm{a}}$ TEF- $1 \alpha=$ translation elongation factor alpha, CSI = chitin synthase I, H3 = histone, TUB = $\beta$-tubulin, and IGS = partial intergenic spacer. 
P. paniculata 'Dunbar Creek' is a commercially available cultivar that is thought to be resistant to PM when planted outdoors $(<25 \%$ infection) (Hawke 2011). It was here used as an internal control.

Five-month-old micropropagated plantlets maintained in tubes containing $15 \mathrm{ml}$ of MS medium were inoculated with nine isolates of G. magnicellulatus and one isolate of Podosphaera sp. in separate experiments as described in Farinas et al. (2019a) (Table 1). Each treatment had six single plantlet replications and each experiment was conducted twice. After inoculation, the plantlets were completely randomized on a laboratory shelf at $24 \pm 1^{\circ} \mathrm{C}$ with a 14-h photoperiod. Latency period (i.e., days between inoculation and sporulation) was visually assessed using a dissecting microscope (Leica S6D, Leica Microsystems Inc., Buffalo Grove, IL) every 4 days, up to 24 days postinoculation (dpi). To measure the latency period, we recorded presence or absence of spores at each evaluation and used the average of all replications $(n=12)$. Disease severity was also visually assessed using a dissecting microscope every 4 days, up to $28 \mathrm{dpi}$. At each rating, the percentage of leaf area covered by PM growth was visually assessed on each individual leaf; values for all leaves were then summed and divided by the number of leaves on each plantlet. Following disease severity ratings, the plantlets were repositioned in the trial. The area under the disease progress curve (AUDPC) was calculated using disease severity ratings at 4-day intervals (Madden et al. 2007). After the final disease severity evaluation, spore production was evaluated using six infected leaves excised from each plantlet $(n=12)$ and placed in individual microcentrifuge tubes containing $0.5 \mathrm{ml}$ of a $0.1 \%$ sterilized Tween 20 water solution to retrieve spores. Tubes were vortexed for $20 \mathrm{~s}$, centrifuged for $2 \mathrm{~min}$ at $21,130 \times g$, and then vortexed again for $5 \mathrm{~s}$. Spores were counted using a hemocytometer and two counts from each tube were averaged. Estimated spore production on each Phlox species was derived by dividing spore counts by the corresponding standardized plant dry weight according to the following formula: average spore number $x$ hemocytometer constant $\times$ volume of spore suspension in tube/ plant dry weight. The dry weight of each Phlox species was assessed by averaging the weight of 12 plantlets (leaves and stems) after $12 \mathrm{~h}$ in an oven at $60^{\circ} \mathrm{C}$.

Data analysis. All statistical analyses were conducted using the R packages agricolae v.1.2.8 (De Mendiburu 2017) and nlme v.

TABLE 3. Phlox germplasm maintained at the Ohio Plant Germplasm Center (OPGC) that was used in this study

\begin{tabular}{llll}
\hline $\begin{array}{l}\text { OPGC accession } \\
\text { number }\end{array}$ & Plant species & $\begin{array}{c}\text { Phlox } \\
\text { subsection }\end{array}$ & $\begin{array}{c}\text { Year and origin } \\
\text { of collection }\end{array}$ \\
\hline 4088 & $\begin{array}{c}\text { P. paniculata } \\
\text { 'Dunbar Creek' }\end{array}$ & Paniculatae & $\begin{array}{c}\text { 1989, Fayette } \\
\text { Co., PA }\end{array}$ \\
4185.7 & P. subulata & Subulatae & $\begin{array}{c}\text { 2013, Vinton } \\
\text { Co., OH }\end{array}$ \\
35943.2 & P. glaberrima & Phlox & 2011, Bullitt \\
& Co., KY \\
3598.6 & P. amoena & Divaricatae & 2011, McCreary \\
& & & Co., KY \\
\hline
\end{tabular}

3.1.131 (Pinheiro et al. 2019) in RStudio v.1.1.383 (RStudio Team 2016). In all experiments, treatment effects on the AUDPC, latency period, and spore production were analyzed by analysis of variance (ANOVA). Tukey's honest significant difference test $(P<0.05)$ was used to test for differences among means. All spore production data were $\log$ transformed to provide better homogeneity of variance prior to ANOVA analysis. The different runs of the experiments were treated as random effects and the treatments as fixed effects. Main effect and interaction of each experiment run was analyzed separately first (Supplementary Table S2), and then the data were pooled together. Regression analysis using mean values was used to analyze the relationship between the spore production data and latency period data collected between 4 and 24 dpi (Chambers 1992).

\section{RESULTS}

Genotype characterization. Polymorphism analysis. In total, we sequenced 3920 nucleotides per pathogen isolate using six genetic markers. Eleven SNPs were observed among isolates in all genes except CSI and H3, which were therefore omitted from further analysis, resulting in 2,785 total nucleotides per isolate. Total haplotype diversity (Hd) was 0.89 . From the concatenated alignment of the four genes, 11 SNPs were identified, or 3.9 SNPs/ $\mathrm{kb}$ (Table 4$)$. TEF- $1 \alpha$ showed the highest number of SNPs $(0.46 \%$ of variable sites) but ITS had the highest number of haplotypes $(n=4)$ and haplotype diversity (0.73) (Table 4). Based on measurement of Tajima's D, none of the genes deviated from neutral evolution (Table 4). TEF-1 $\alpha$ had the greatest nucleotide polymorphism (1.25) and the greatest pairwise nucleotide diversity with ITS $(0.002$ and 0.0022 , respectively). Overall, low genetic diversity was detected in our population.

A total of 221,982 SNPs was found in isolate $\mathrm{OH} 2$ when mapped to the reference genome $\mathrm{OH} 1$, which corresponds to $1.7 \mathrm{SNPs} / \mathrm{kb}$. Of the total number of SNPs, $77.4 \%$ were located in the intergenic regions, $2.7 \%$ were located in exons, and $0.4 \%$ were located in introns, which represent 1.3, 0.046, and 0.007 SNPs/kb, respectively. The ratio of nonsynonymous versus synonymous substitutions (dN/dS) was 0.822. Additionally, 69,550 insertions and 805,503 deletions were found. A tBLASTn comparison of $\mathrm{OH} 1$ secreted proteins against the $\mathrm{OH} 2$ draft assembly recovered only 285 out of 292 proteins. The seven proteins missing from $\mathrm{OH} 2$ have predicted functions such as putative oxidoreductase (KND86368.1), glycoside hydrolase (OAA42022.1), putative effector protein (RKF82013.1), SGNH hydrolase-type (OAA72930.1), chitinase (OAQ87645.1), cell wall galactomannoprotein (OAA35810), and biotrophy-associated secreted protein (XP008096078.1).

Phylogenetic analysis. Phylogenetic incongruence was observed among the maximum likelihood trees obtained from the different genes (Fig. 1 and Supplementary Fig. S1). Only phylogenetic trees based on ITS and TEF- $1 \alpha$ provided any phylogenetic resolution (Fig. 1). Gene tree topologies conflicted with regards to the placement of $\mathrm{OH} 4, \mathrm{OH} 5, \mathrm{OH} 2, \mathrm{IA} 1$, and WI1 isolates.

TABLE 4. Basic diversity indices calculated in the phylogenetic analysis conducted in this study

\begin{tabular}{|c|c|c|c|c|c|c|c|c|}
\hline \multirow[b]{2}{*}{ Locus $^{\mathrm{a}}$} & \multirow[b]{2}{*}{ Length (bp) } & \multicolumn{7}{|c|}{ Sequence diversity index ${ }^{b}$} \\
\hline & & SNPs $(\%)$ & Tajima's D & $\mathrm{H}$ & $\mathrm{Hd}$ & $\mathrm{k}$ & $\pi$ & $\theta_{w}$ \\
\hline TEF- $1 \alpha$ & 1,080 & $5(0.46)$ & 1.79 & 3 & 0.54 & 2.08 & 0.002 & 1.25 \\
\hline TUB & 668 & $2(0.29)$ & -1.26 & 3 & 0.32 & 0.19 & 0.00028 & 0.5 \\
\hline IGS & 477 & $1(0.2)$ & -1.15 & 2 & 0.065 & 0.06 & 0.00014 & 0.25 \\
\hline Concatenated & 2,785 & $11(0.4)$ & 0.91 & 12 & 0.89 & 3.5 & 0.001 & 2.75 \\
\hline
\end{tabular}


According to neighbor-net phylogenetic network analysis (Fig. 2 ), where the nodes represent the samples haplotypes and the edges represent the evolutionary relationship, a closed loop, or reticulation, was observed. Isolates with dot numbers (i.e., isolates retrieved from different leaves of the same plant sample) grouped together (i.e., OH4.1-3), indicating clonality among the isolates. Isolates from Mississippi and Tennessee, representing hardiness zones 7 and 8, grouped together, whereas all isolates in hardiness zones 5 and 6 have no apparent population structure.

Phenotype characterization. Phlox germplasm screening. Across both experimental runs, the main and interaction effects of
PM isolate $(n=10)$ and Phlox species $(n=4)$ on AUDPC were highly significant $(P<0.001$; Supplementary Table S2). The data from the two experimental runs were pooled (Table 5), and the AUDPC for all PM isolates was assessed by Phlox species (Fig. 3). Phlox paniculata showed consistently low AUDPC across all isolates with MI1 isolate having a significantly higher mean value $(P=0.001)$. P. amoena also showed overall low AUDPC values for all but three G. magnicellulatus isolates, (MI1, OH1, and $\mathrm{OH} 4.1$, corresponding to 16,14 , and $7.3 \%$ final disease severity, respectively; $P<0.001)$. In $P$. subulata, AUDPC values were overall slightly higher compared with $P$. paniculata and $P$. amoena
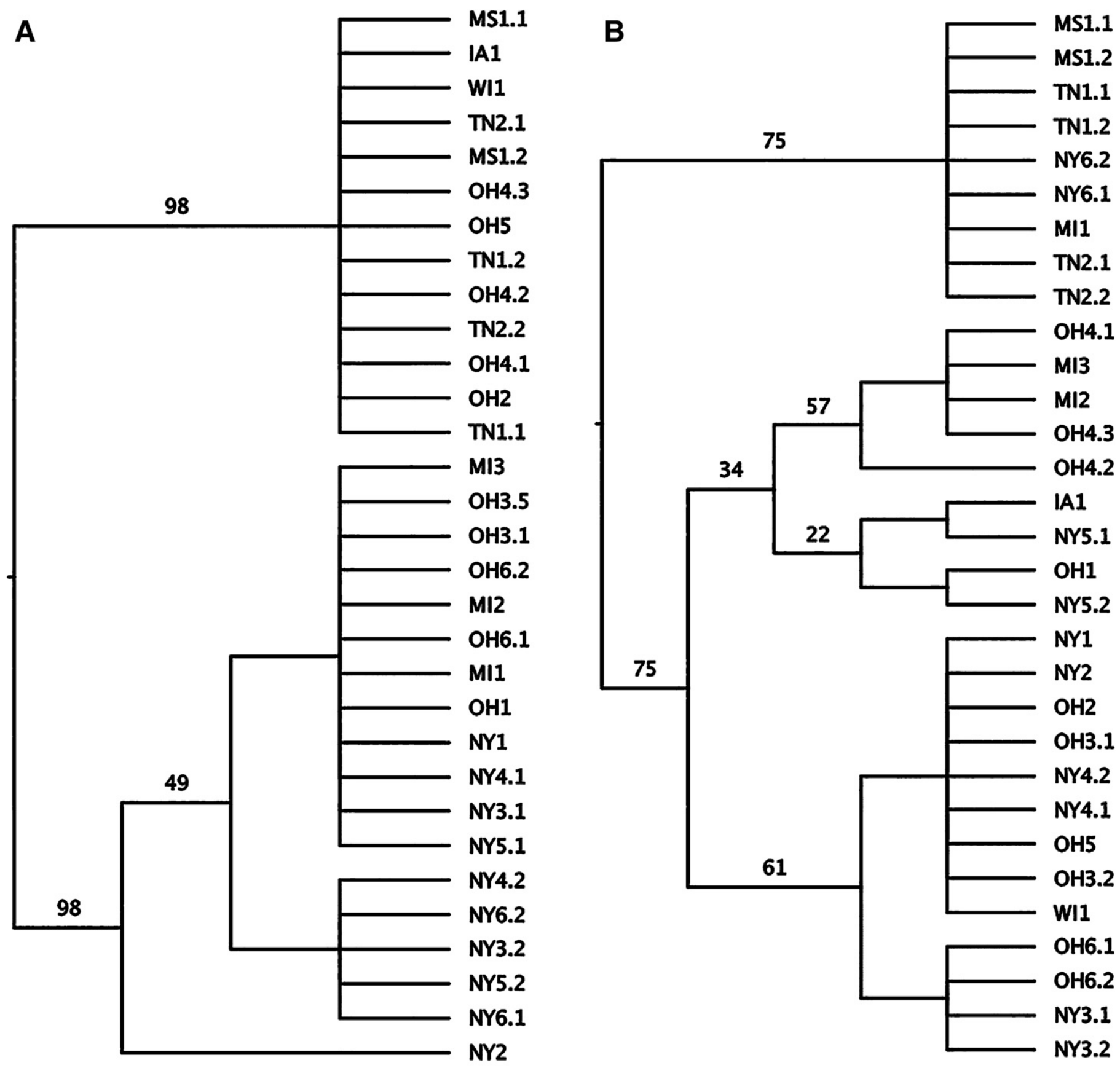

0.2

0.2

Fig. 1. Cladogram representation of maximum likelihood phylogenetic trees generated from A, translation elongation factor alpha (TEF-1 $\alpha$ ) and $\mathbf{B}$, internal transcribed spacer (ITS) sequences using 31 Golovinomyces magnicellulatus isolates with 100 bootstrap support. 
and there was a significant difference between isolate OH1 (25.4\% final disease severity) and isolates IA1 (4.3\%), MI1 (2.9\%), OH2 (3.6\%), as well as Podosphaera sp. isolate VA1 $(1.1 \% ; P=0.005)$. $P$. glaberrima showed varying responses; low AUDPC was recorded when infected with $G$. magnicellulatus isolates IA1 (3.3\% final disease severity), MS1.1 (2.3\%), NY1 (0.2\%), and OH3.1 (3.1\%), as well as Podosphaera sp. isolate VA1 (3.3\%), while a very high value was recorded when the species was infected with isolate MI1 $(35.2 \% ; P<0.001)$.

When comparing latency periods, the main and interaction effects of PM isolate $(n=10)$ and Phlox species $(n=4)$ were highly significant across both experimental runs $(P<0.001$; Supplementary Table S2). The data from the two experimental runs were pooled (Table 5), and the latency period for all PM isolates was assessed by Phlox species (Fig. 4). Across all four Phlox species, $P$. amoena and $P$. paniculata had a significantly longer latency period than $P$. glaberrima and $P$. subulata $(P<0.001$; Fig. 4$)$.

Finally, when comparing spore production, the interaction effect of PM isolate $(n=10)$ and Phlox species $(n=4)$ was only significant in the second experimental run $(P<0.001$; Table S2). The data from the two experimental runs were pooled (Table 5). A negative relationship $\left(r^{2}=0.99\right)$ was observed between the average number of spores produced per mg of dry weight and the latency period (4 to $24 \mathrm{dpi}$ ), indicating that a lower number of spores was observed when it took longer for PM to sporulate (Fig. 5).

\section{DISCUSSION}

This study is the first to characterize Phlox germplasm in vitro by identifying resistant traits in four Phlox species using several PM pathogen isolates. Moreover, it is the first to identify the diversity of the pathogen to infer durability of host resistance.

The population sampling used in this study was both spatial, encompassing eight U.S. states including four different hardiness zones (5 through 8 ), and temporal, as it was performed throughout

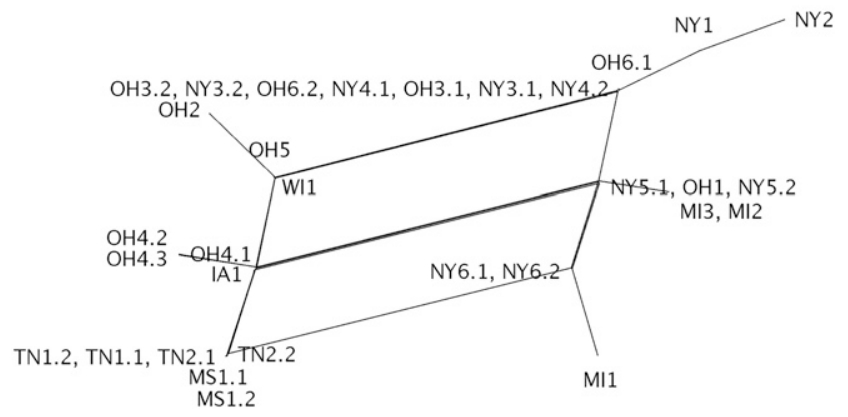

Fig. 2. Neighbor-net phylogenetic network computed with SplitTree using concatenated sequences of four genes (translation elongation factor alpha $[$ TEF-1 $\alpha$ ], internal transcribed spacer [ITS], intergenic spacer [IGS], and $\beta$-tubulin $[\mathrm{TUB}]$; Fit $=97.6 \%$ ). Nodes in the phylogenetic network represent the sample haplotypes, and the edges represent the evolutionary relationship among isolates. four growing seasons (from 2016 to 2019). Six genetic markers were used in this study (TEF-1 $\alpha$, CSI, TUB, IGS, H3, and ITS), among which TEF- $1 \alpha$ and ITS were the most informative. In our study, several isolates were sometimes retrieved from the same plant sample. Those isolates did not show genetic variation from one another, suggesting that they may have been clonally reproduced.

Gene trees did not recover consistent evolutionary relationships among certain $G$. magnicellulatus isolates and were generally poorly resolved. We therefore used a neighbor-net phylogenetic network analysis to further visualize our population structure. Neighbor-net phylogenetic network analyses are thought to deal with systematic errors that tree-based phylogenetic analyses are not protected from, such as mistakes in assumptions of a model (Huson and Bryant 2006). Closed loops, or reticulations in the network demonstrate phylogenetic disagreement among polymorphic loci and could be the result of recombination, recurrent and/or reverse mutations (Milgroom 2015), or incomplete lineage sorting of alleles. The availability of fungal tissue, genetic distance, contrasting phenotypic differences, and sympatric diversification were taken into consideration when choosing isolates $\mathrm{OH} 1$ and $\mathrm{OH} 2$ to provide a more in-depth analysis of overall SNP diversity among isolates in our population. Lower genetic diversity was observed between these two genotypes (1.6 SNPs/kb) compared with what was observed in the whole population with the MLST analysis using all six loci (2.8 SNPs/kb). Other genomic comparison studies have found an average of $1 \mathrm{SNP} / \mathrm{kb}$ between three barley PM pathogen isolates (Hacquard et al. 2013), and between 0.1 to $1.1 \mathrm{SNPs} / \mathrm{kb}$ depending on the region of the wheat PM pathogen genome (Wicker et al. 2013). Wicker et al. (2013) suggested that the three isolates used in their study represent two haplogroups.

Discordant phylogenetic trees, along with a reticulated SNP network, suggest that the population is recombining. The low SNP density across the North East United States is consistent with recent dispersal among states via horticultural trade. Indeed, Phlox plants are grown in production facilities and shipped across and between states to retailer facilities. Because of the disease latency period, sometimes there are few or no signs of the pathogen on even infected plants. Unknowingly shipping infected plant material can therefore contribute to the spread of the pathogen. Sexual recombination and the genotypic diversity that results may allow populations to adapt to changing environments and to new resistant cultivars. Indeed, according to the risk model proposed by McDonald and Linde (2002), pathogens undergoing recombination events have a higher risk of evolution, and recombined genotypes may result in new avirulence genes. However, in stable environments, recombinant genotypes would be less fit than their parents, reducing the advantage of sexual recombination (Milgroom 2015).

Strict clonality, as seen with some isolates recovered from the same plant sample (i.e., OH3.1-2), is at the opposite end of the spectrum from random mating. PMs are well known for producing numerous asexual spores during the growing season, which results in large, clonal populations. Hence, it appears that our Phlox PM population is navigating the continuum between random mating and strict clonality. New questions arise from our results;

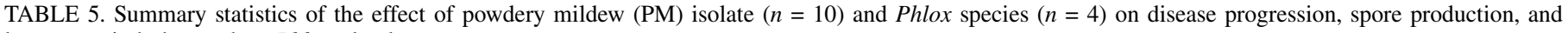
latency period observed on Phlox plantlets

\begin{tabular}{|c|c|c|c|c|c|c|}
\hline \multirow[b]{2}{*}{ Factor } & \multicolumn{2}{|c|}{ AUDPC $^{\mathrm{a}}$} & \multicolumn{2}{|c|}{ Spore production $^{\mathrm{b}}$} & \multicolumn{2}{|c|}{ Latency period $^{\mathrm{c}}$} \\
\hline & $F$ value & $P$ value & $F$ value & $P$ value & $F$ value & $P$ value \\
\hline PM isolate & 12.7 & $<0.001$ & 9.6 & $<0.001$ & 8.9 & $<0.001$ \\
\hline Phlox species & 14.7 & $<0.001$ & 17.4 & $<0.001$ & 25.9 & $<0.001$ \\
\hline PM isolate $\times$ Phlox species & 4.3 & $<0.001$ & 3.4 & $<0.001$ & 4.2 & $<0.001$ \\
\hline
\end{tabular}

a AUDPC $=$ area under the disease progress curve. Values were calculated from disease severity data collected at 28 days postinoculation.

b Amount of spore produced per milligram of plant dry weight 28 days postinoculation. Data were log-transformed prior to analysis of variance.

c Latency period corresponds to the number of days between inoculation and sporulation. 
specifically, has our population recently evolved from an ancestral population, and could there be a population structure reflecting different hardiness zones?

In this study, P. paniculata 'Dunbar Creek', which we used as a control in our germplasm screening, consistently showed low AUDPC when inoculated with different PM isolates in a highly disease conducive environment. This indicates that this cultivar was the most resistant host among four different Phlox species tested. Based on the small AUDPC value variation between isolates (some degree of resistance within all PM isolates), $P$. subulata showed quantitative resistance, $P$. amoena showed qualitative resistance due to its drastic AUDPC value differences between PM isolates (resistant or susceptible), and P. glaberrima seemed to have both quantitative and qualitative resistance to some PM pathogen isolates.

It should be noted that isolate $\mathrm{OH} 4.1$ was originally retrieved from P. paniculata 'David', a cultivar chosen as the 2002 Perennial Plant of the Year (Perennial Plant Association 2002). This cultivar was initially marketed as highly resistant to PM but has lost its resistance over the years since cultivar introduction. Changes in aggressiveness of pathogens selected by quantitative resistance is a highly studied phenomenon with conflicting results (Cowger and Brown 2019; Delmas et al. 2016). Interestingly, in this study, OH4.1 was not the most aggressive isolate. This study suggests that there is a genetic basis of resistance in Phlox germplasm, emphasizing the advantage of using available germplasm when breeding for resistance. The species $P$. amoena and $P$. glaberrima are rarely, if at all, used when breeding for new cultivars of garden Phlox. Combinations of genes for resistance, or gene pyramids, are often used to obtain durable resistance (Mundt 2014), and individuals of these species could supply desirable genes. With our germplasm screening experiment, we also identified high phenotypic diversity among PM isolates, despite the low genetic diversity found with our MLST analysis and a pairwise whole genome SNP comparison.
However, in a whole genome comparison of two sympatric PM pathogen isolates $(\mathrm{OH} 1$ and $\mathrm{OH} 2)$, we identified 7 of 292 predicted secreted proteins in $\mathrm{OH} 1$ that are absent from an assembly of $\mathrm{OH} 2$, which could in part explain the observed phenotypic diversity among isolates. Indeed, the predicted functions of these secreted proteins are consistent with effectors and enzymes that may facilitate the infection process or impact the success of quantitative plant defense compounds. Such compositional diversity among isolates has been shown to facilitate rapid evolution in populations of plant pathogens undergoing sexual and parasexual recombination (Plissonneau et al. 2018).

When looking at the latency period data, we saw that $P$. paniculata and $P$. amoena show higher resistance compared with

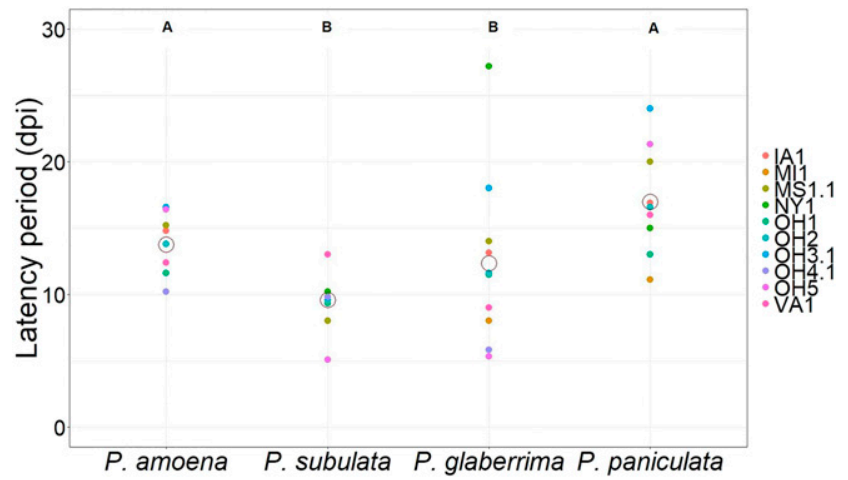

Fig. 4. Scatter plot chart of days between inoculation and sporulation (i.e., latency period), expressed as days postinoculation (dpi), observed among powdery mildew (PM) isolates on each Phlox species. Each dot represents the mean of 12 data points. Large empty circles in each species indicate mean values.

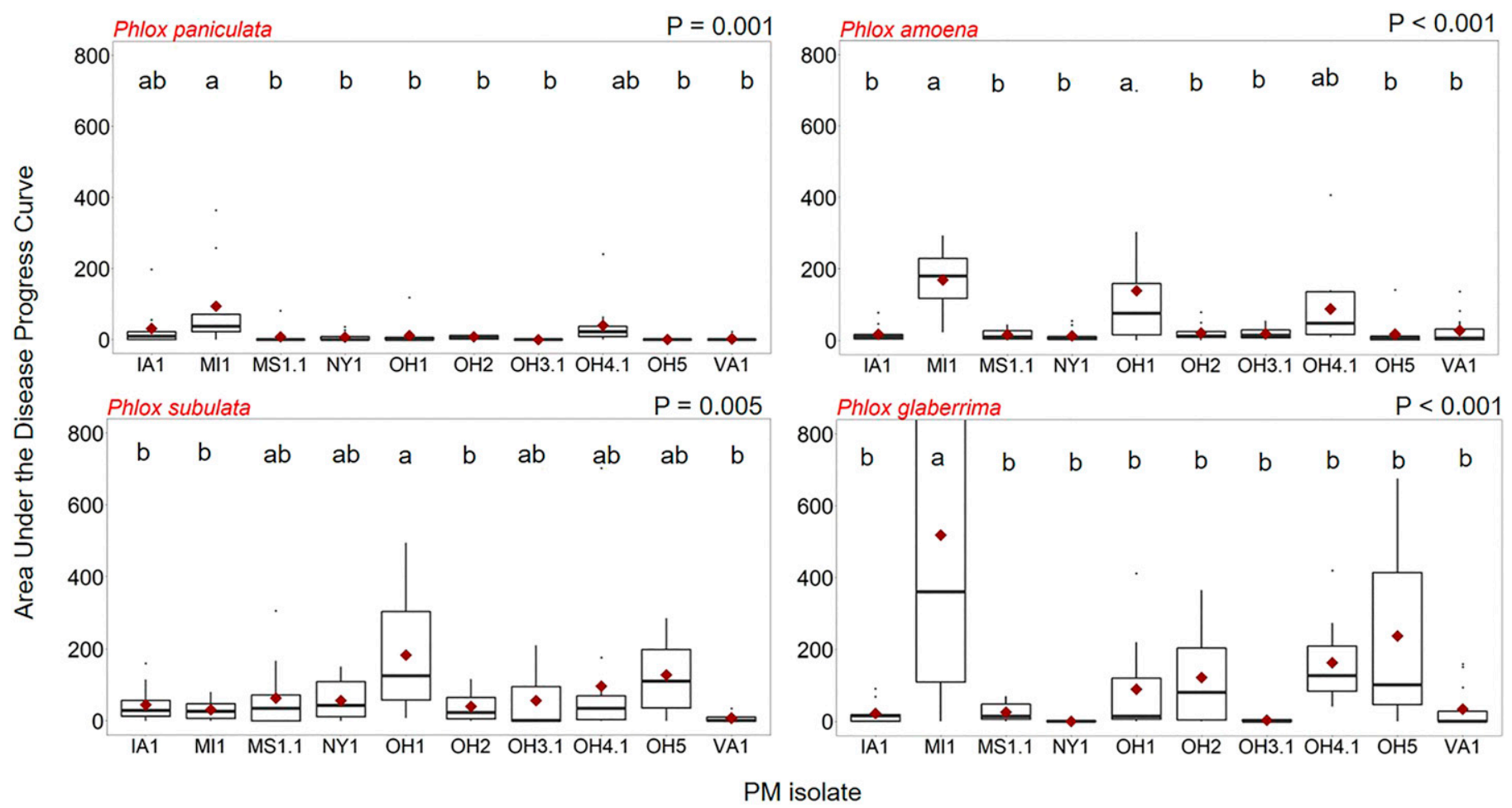

Fig. 3. Boxplots of the area under the disease progress curve (AUDPC) assessed for 28 days postinoculation as observed among powdery mildew (PM) isolates. Boxplots followed by the same letter are not statistically different according to Tukey's honest significant difference test $(\alpha=0.05)$. The horizontal line in each boxplot represents the median, and the box's lower and upper line represent the lower and the upper quartile at 0.25 and 0.75 . The whiskers represent the minimum and maximum values. Dots outside of the boxplots represent outliers, and rhombus dots inside the boxplot indicate mean values. Maximum AUDPC value for isolate MI1 (1184.3) is not shown in the chart. 


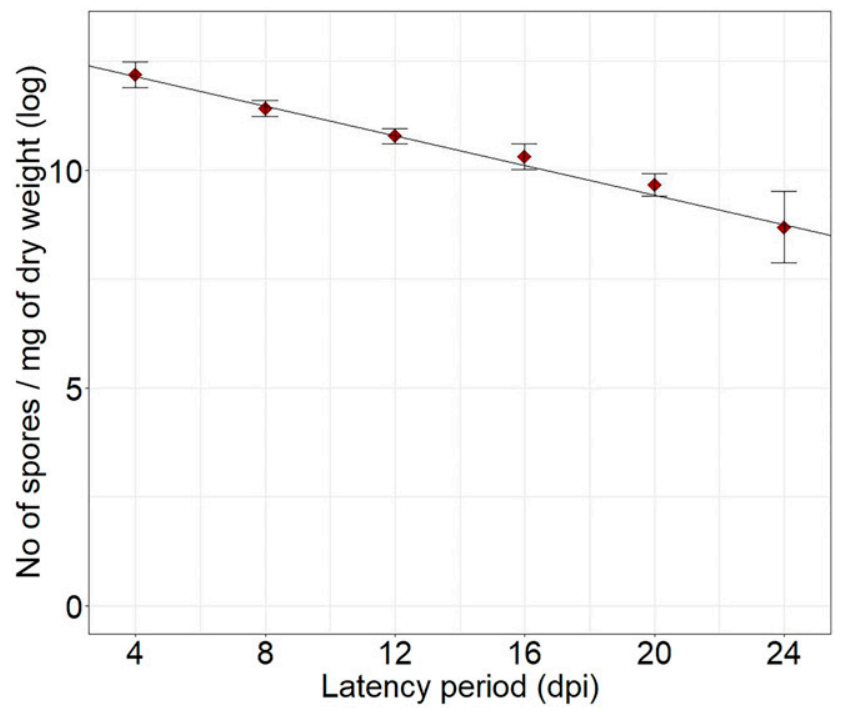

Fig. 5. Linear regression showing the relationship between the amount of spores produced on all infected plantlets from all Phlox species $(n=480) 28$ days postinoculation (dpi) and the latency period (i.e., days between inoculation and sporulation; 4 to $24 \mathrm{dpi} ; P<0.001$; intercept 12.8 ; slope -0.17 ; and $r^{2}=0.99$ ). Rhombus dots correspond to mean values \pm standard error.

P. glaberrima and $P$. subulata. Latency period and number of spores produced are important factors in predicting epidemics. Longer latency periods and lower number of spores produced can slow down an epidemic's rate of progress and confer better host performance in the landscape (Delmas et al. 2016). Epidemic frequency as well as mixed reproductive models mentioned above are crucial characteristics to consider when assessing the durability of quantitative resistance (Cowger and Brown 2019). This study is the first to use an in vitro tool to characterize Phlox germplasm for its resistance to $\mathrm{PM}$ and to identify resistance patterns to inform future breeding programs. Moreover, this study laid a foundation for characterizing the G. magnicellulatus population present in the eastern United States. Further studies with higher number of PM isolates and Phlox species as well as herbarium specimens infected with PM could help understand the movement and origin of $G$. magnicellulatus. The results of this study, taken together, set a strong foundation that will contribute to further research tackling the major challenges in PM pathogen genomics, identified by Bindschedler et al. (2016), including the understanding and analysis of genome variation and evolutionary potential of PM pathogens.

\section{ACKNOWLEDGMENTS}

We thank Lewis Ginter Botanical Garden (VA), Boerner Garden (WI), Dow Gardens (MI), Holden Arboretum (OH), and Franklin Park Conservatory $(\mathrm{OH})$, as well as all the commercial nurseries and retailers that provided us with PM-infected samples.

\section{LITERATURE CITED}

Armitage, A. M. 2008. Pages 787-800 in: Herbaceous Perennial Plants. A Treatise on Their Identification, Culture, and Garden Attributes, 3rd Ed. Stipes Publishing Co., Champaign, IL.

Bindschedler, L. V., Panstruga, R., and Spanu, P. D. 2016. Mildew-omics: How global analyses aid the understanding of life and evolution of powdery mildews. Front. Plant Sci. 7:123.

Capella-Gutierrez, S., Silla-Martinez, J. M., and Gabaldon, T. 2009. trimAl: A tool for automated alignment trimming in large-scale phylogenetic analyses. Bioinformatics 25:1972-1973.

Cartwright, J., Robbins, G., and Klingaman. 2001. Evaluation of Phlox paniculata cultivars for susceptibility to powdery mildew. Pages 95-96 in: Horticultural Studies 2001, University of Arkansas.
Chambers, J. M. 1992. Linear models. Chapter 4 of Statistical Models in S. J. M. Chambers and T. J.Hastie, eds. Wadsworth \& Brooks/Cole Advanced Books \& Software, Springer.

Chernomor, O., von Haeseler, A., and Minh, B. Q. 2016. Terrace aware data structure for phylogenomic inference from supermatrices. Syst. Biol. 65: 997-1008.

Coombs, G. 2017. Phlox for the mid-Atlantic region. Research Report. Mt. Cuba Center, Hockessin, DE.

Cowger, C., and Brown, J. K. 2019. Durability of quantitative resistance in crops: Greater than we know? Annu. Rev. Phytopathol. 57:253-277.

Danecek, P., Auton, A., Abecasis, G., Albers, C. A., Banks, E., DePristo, M. A., Handshaker, R. E., Lunter, G., Marth, G. T., Sherry, S. T., McVean, G., and Durbin, R. 2011. The variant call format and VCF tools. Bioinformatics 27:2156-2158.

De Mendiburu, F. 2017. Agricolae: Statistical procedures for agricultural research. R package version 1.2-8. https://cran.r-project.org/web/packages/ agricolae/index.html

Delmas, C. E., Fabre, F., Jolivet, J., Mazet, I. D., Richart Cervera, S., Deliere, L., and Delmotte, F. 2016. Adaptation of a plant pathogen to partial host resistance: Selection for greater aggressiveness in grapevine downy mildew. Evol. Appl. 9:709-725.

Farinas, C., Gluck-Thaler, E., Slot, J. C., and Peduto Hand, F. 2019b. Wholegenome sequence of the Phlox powdery mildew pathogen Golovinomyces magnicellulatus strain FPH2017-1. Microbiol. Resour. Announc. 8: e00852-e19.

Farinas, C., Jourdan, P., Paul, P. A., and Peduto Hand, F. 2019a. Development and evaluation of laboratory bioassays to study powdery mildew pathogens of Phlox in vitro. Plant Dis. 103:1536-1543.

Goss, E. M., Larsen, M., Chastagner, G. A., Givens, D. R., and Grünwald, N. J. 2009. Population genetic analysis infers migration pathways of Phytophthora ramorum in US nurseries. PLoS Pathog 5:e1000583.

Hacquard, S., Kracher, B., Maekawa, T., Vernaldi, S., Schulze-Lefert, P., and van Themaat, E. V. L. 2013. Mosaic genome structure of the barley powdery mildew pathogen and conservation of transcriptional programs in divergent hosts. Proc. Natl. Acad. Sci. 110:E2219-E2228.

Hawke, R. 1999. Plant evaluation notes. An evaluation report of selected Phlox species and hybrids. Chicago Botanic Garden, Issue 13.

Hawke, R. 2011. A comparative study of Phlox paniculate cultivars. Chicago Botanic Garden. Plant Evaluation Notes, Issue 35.

Huson, D. H., and Bryant, D. 2006. Application of phylogenetic networks in evolutionary studies. Mol. Biol. Evol. 23:254-267.

Ji, X., Xie, C., Ni, Z., Yang, T., Nevo, E., Fahima, T., Liu, Z., and Sun, Q. 2008. Identification and genetic mapping of a powdery mildew resistance gene in wild emmer (Triticum dicoccoides) accession IW72 from Israel. Euphytica 159:385-390.

Lanfear, R., Calcott, B., Ho, S. Y., and Guindon, S. 2012. Partition Finder: Combined selection of partitioning schemes and substitution models for phylogenetic analyses. Mol. Biol. Evol. 29:1695-1701.

Langmead, B., Wilks, C., Antonescu, V., and Charles, R. 2018. Scaling read aligners to hundreds of threads on general-purpose processors. Bioinformatics 35:421-432.

Li, H., Handsaker, B., Wysoker, A., Fennell, T., Ruan, J., Homer, N., Marth, G., Abecasis, G., Durbin, R., and 1000 Genome Project Data Processing Subgroup. 2009. The Sequence alignment/map (SAM) format and SAMtools. Bioinformatics 25:2078-2079.

Librado, P., and Rozas, J. 2009. DNASP v5: A software for comprehensive analysis of DNA polymorphism data. Bioinformatics 25:1451-1452.

Madden, L. V., Hughes, G., and van den Bosch, F. 2007. The Study of Plant Disease Epidemics. American Phytopathological Society, St. Paul, MN.

Matsuda, S., and Takamatsu, S. 2003. Evolution of host-parasite relationships of Golovinomyces (Ascomycete: Erysiphaceae) inferred from nuclear rDNA sequences. Mol. Phylogenet. Evol. 27:314-327.

McDonald, B. A., and Linde, C. 2002. Pathogen population genetics, evolutionary potential, and durable resistance. Annu. Rev. Phytopathol. 40:349-379.

Milgroom, M. G. 2015. Population Biology of Plant Pathogens: Genetics, Ecology, and Evolution. American Phytopathological Society, St. Paul, $\mathrm{MN}$

Mundt, C. C. 2014. Durable resistance: A key to sustainable management of pathogens and pests. Infect. Genet. Evol. 27:446-455.

Nei, M. 1987. Molecular Evolutionary Genetics. Columbia University Press, New York.

Parke, J., and Grünwald, N. J. 2012. A systems approach for management of pests and pathogens of nursery crops. Plant Dis. 96:1236-1244.

Perennial Plant Association. 2002. Perennial Plant of the year award. Perennial Plant Association. https://perennialplant.org/page/pastwinners

Pinheiro, J., Bates, D., DebRoy, S., and Sarkar, D. 2019. nlme: Linear and Nonlinear Mixed Effects Models. R package version 3.1-141. https://cran.rproject.org/web/packages/nlme/index.html 
Pirondi, A., Kitner, M., Iotti, M., Sedláková, B., Lebeda, A., and Collina, M. 2016. Genetic structure and phylogeny of Italian and Czech populations of the cucurbit powdery mildew fungus Golovinomyces orontii inferred by multilocus sequence typing. Plant Pathol. 65:959-967.

Plissonneau, C., Hartmann, F. E., and Croll, D. 2018. Pangenome analyses of the wheat pathogen Zymoseptoria tritici reveal the structural basis of a highly plastic eukaryotic genome. BMC Biol. 16:5.

RStudio Team. 2016. RStudio: Integrated Development for R. RStudio, Inc., Boston, MA. http://www.rstudio.com/

Rambaut, A., Drummond, A., Xie, D., Baele, G., and Suchard, M. 2018. Posterior summarization in Bayesian phylogenetics using tracer 1.7. Syst. Biol. 67:901-904.

Reddy, K. P., Rao, S. C., Kirti, P. B., and Sujatha, M. 2013. Development of a scoring scale for powdery mildew (Golovinomyces cichoracearum (DC.) VP Heluta) disease and identification of resistance sources in cultivated and wild sunflowers. Euphytica 190:385-399.

Spanu, P. D., Abbott, J. C., Amselem, J., Burgis, T. A., Soanes, D. M., Stüber, K., van Themaat, A. V. L., Brown, J. K. M., Butcher, S. A., Gurr, S. J., Lebrun, M. H., Ridout, C. J., Schulze-Lefert, P., Talbot, N. J., Ahmadinejad, N., Ametz, C., Barton, G. R., Benjdia, M., Bidzinski, P., Bindschedler, L. V., Brewer, M., Cadle-Davidson, L., Cadle-Davidson, M. M., Collemare, J., Cramer, R., Frenkel, O., Godfrey, D., Harriman, J., Hoede, C., King, B., Klages, S., Kleemann, J., Knoll, D., Koti, P.S., Kreplak, J., López-Ruiz, F. J., Lu, X., Maekawa, T., Mahanil, S., Micali, C., Milgroom, M. G., Montana, G., Noir, S., O’Connell, R. J., Oberhaensli, S., Parlange, F., Pedersen, C., Quesneville, H., Reinhardt, R., Rott, M., Sacristán, S., Schmidt, S. M., Schön, M., Skamnioti, P., Sommer, H., Stephens, A., Takahara, H., Thordal-Christensen, H., Vigouroux, M., Weßling, R., Wicker, T., and Panstruga, R. 2010. Genome expansion and gene loss in powdery mildew fungi reveal tradeoffs in extreme parasitism. Science 330: 1543-1546.

Katoh, K., and Standley, K. 2013. MAFFT multiple sequence alignment software version 7: Improvements in performance and usability. Mol. Biol. Evol. 30:772-780.

Šurlan-Momirović, G., Flath, K., Silvar, C., Branković, G., Kopahnke, D., Knežević, D., Schliephake, E., Ordon, F., and Perović, D. 2016. Exploring the Serbian GenBank barley (Hordeum vulgare L. subsp. vulgare) collection for powdery mildew resistance. Genet. Resour. Crop Evol. 63: 275-287.

Tajima, F. 1983. Evolutionary relationship of DNA sequences in finite populations. Genetics 105:437-460.

Tajima, F. 1989. Statistical methods to test for nucleotide mutation hypothesis by DNA polymorphism. Genetics 123:585-595.

Takamatsu, S., Matsuda, S., Niinomi, S., and Havrylenko, M. 2006. Molecular phylogeny supports a northern hemisphere origin of Golovinomyces (Ascomycota: Erysiphales). Mycol. Res. 110:1093-1101.

Thompson, H. S., and Svejda, F. J. 1964. Resistance to powdery mildew in perennial Phlox. Can. J. Plant Sci. 45:258-263.

Vaz Patto, M. V., Fernández-Aparicio, M., Moral, A., and Rubiales, D. 2007. Resistance reaction to powdery mildew (Erysiphe pisi) in a germplasm collection of Lathyrus cicera from Iberian origin. Genet. Resour. Crop Evol. 54:1517-1521.

Walsh, P. S., Metzger, D. A., and Higuchi, R. 1991. Chelex 100 as a medium for simple extraction of DNA for PCR-based typing from forensic material. Biotechniques 10:506-513.

Watterson, G. A. 1975. On the number of segregating sites in genetical models without recombination. Theor. Popul. Biol. 7:256-276.

White, T. J., Bruns, T. D., Lee, S., and Taylor, J. 1990. Amplification and direct sequencing of fungal ribosomal genes for phylogenetics. Pages 315-322 in: PCR Protocols: A Guide to Methods and Applications. M. A. Innis, D. H. Gelfand, J. J. Sninsky, and T. J. White, eds. Academic Press, San Diego, CA.

Wicker, T., Oberhaensli, S., Parlange, F., Buchmann, J. P., Shatalina, M., Roffler, S., Ben-David, R., Doležel, J., Šimková, H., Schulze-Lefert, P., Spanu, P. D., Bruggmann, R., Amselem, J., Quesneville, H., van Themaat, E. V. L., Paape, T., Shimizu, K. K., and Keller, B. 2013. The wheat powdery mildew genome shows the unique evolution of an obligate biotroph. Nat. Genet. 45:1092-1096.

Zale, P., and Jourdan, P. 2015. Genome size and ploidy and Phlox paniculata and related germplasm in subsections Paniculatae and Phlox. J. Am. Soc. Hortic. Sci. 140:436-448. 